\title{
Perceived Parental Monitoring on Adolescence Premarital Sexual Behavior in Pontianak City, Indonesia
}

\author{
Linda Suwarni $^{1}$, Djauhar Ismail ${ }^{2}$, Yayi Suryo Prabandari ${ }^{2}$, MG Adiyanti ${ }^{3}$ \\ ${ }^{1}$ Department of Public Health Science, Universitas Muhammadiyah Pontianak, Indonesia \\ ${ }^{2}$ Departement of Medical, Gadjah Mada University, Indonesia \\ ${ }^{3}$ Departement of Psychology, Gadjah Mada University, Indonesia
}

\section{Article Info}

Article history:

Received Jul 24, 2015

Revised Aug 20, 2015

Accepted Aug 30, 2015

\section{Keyword:}

Adolescent

Attitude

Intention

Parental monitoring

Premarital sexual

\begin{abstract}
Inadaquate parental monitoring is widely recognized as a risk factor for the development of child and adolescent conduct problems, including early premarital sexual behavior. Previous studies examining parental monitoring have largely effect to adolescents' premarital sexual behavior. Parental monitoring is the most important and effective factor to prevent early adolescents sexual activity. This paper examines the role of perceived parental monitoring in adolescent's premarital sexual behavior (study on Adolescent's Junior High School in Pontianak). A cross-sectional study and proportionated random sampling was conducted among 402 adolescents of junior high school at six subdistricts in Pontianak. SEM analyses was conducted using SMART-PLS. Result of path analysis revealed that parental knowledge $(r=0.389)$ and parental-adolescence relationship $(r=0.334)$ had a strong influence on parental monitoring. Then, parental monitoring had a significant indirect relationship with adolescent premarital sexual behavior through attitudes about premarital sexual (path coefficient $=0.063$ ), and attitudes about premarital sexual and intention to sexual behaviour (path coefficient $=0.03$ ). Parental monitoring can act as protective factor in early adolescent premarital sexual behavior. Therefore, risk reduction interventions with adolescents should include their parents to learn about monitoring skill and develop skill that will allow them to buffer negative influences.
\end{abstract}

Copyright (c) 2015 Institute of Advanced Engineering and Science. All rights reserved.

\section{Corresponding Author:}

Linda Suwarni,

Department of Public Health Science,

Universitas Muhammadiyah Pontianak,

A. Yani Street Number 111 Pontianak, West Kalimantan, Indonesia.

Email: lienharis@yahoo.co.id

\section{INTRODUCTION}

Reproductive Health has special attention globally since the International Conference on Population and Development in Cairo, Egypt [1]. One of the results of this conference was focusing on adolescent reproductive health. Population Reference Bureaus (2013) showed the number of adolescents (10-24 years old) about 1.809 billion (25\% of total population in Asia, including Indonesia) [2]. It indicates that proportion of adolescent is high in the population of world, including Indonesia. Adolescence is an investment in the future, who will facilitate the achievement of Millenium Development Goal (MDGs) [1].

According to Youth Risk Behavior Survey in 2005, the prevalence of adolescents in the world who ever had sexual intercourse was $35.7 \%$ to $55.1 \%$, and about $2.8 \%-10.8 \%$ of them had sex less than 13 years [3]. Early adolescents sexual intercourse have an impact on their reproductive health. Adolescents who have sexual intercouse earlier is associated with low contraception using and most of them have more than one sexual partners [4],[5]. Adolescences perform varies sexual initiations age in different countries. The age of sexual initiation among adolescents is ranging from 12 to 19 years [4]-[9]. 
Indonesian Adolescent Reproductive Health Survey in 2007 showed that sexual behavior among adolescents were kissing (30.9\% male and 23.2\% female) and petting (19.2\% males and 6.5\% females) [10]. Moreover, the results of Health Research (2010) indicates that about 1\% of male and 4\% of female in Indonesia have had sexual intercourse before 13 years old, while the others under 10 years old (4). Adolescents (13-14 years old) are reported nearly 4\% have had sexual intercourse and its percentage relatively increases with the age [11].

Adolescents sexual behavior in West Kalimantan is not much different compared with sexual behavior of adolescents in Indonesia. The proportion of adolescent population (10-24 years) approximately $29.32 \%$ of total population in West Kalimantan [12]. Adolescent premarital sexual behaviour in Pontianak (2009) showed that 56.9\% adolescents had been kissing, 30.2\% necking, 13.8\% petting, 7.2\% oral sex, 5.5\% anal sex, and $14.7 \%$ intercourse. The number of intercourse is higher than the number of intercourse by the ministry of Health (6.9\% in Jakarta, Medan, Bandung, and Surabaya) [13].

Adolescents premarital sexual behavior becomes serious problem. There is a phenomenon of this in society, called "cabe-cabean". Definition of premarital sexual behavior is all forms of sexual behavior that comes from sexual desire in the opposite sex by adolescents before marriage, either from performing the less intimate relationships to performing sexual intercourse (kissing, necking, petting, and intercourse) [14]. Adolescent sexual behaviors from kissing to touching sensitive areas, will often continue to sexual intercourse [15],[16].

Risk factors and protective factors influence the occurrence of premarital sexual behavior in adolescents [17],[18]. Family environment is a protective factor and prevention of risky behavior in adolescents [19],[20]. Moreover, family is the main factor affecting adolescence development, although they are also influenced by peers, school friends and the society.

Monitoring parental to adolescent is significantly associated with adolescent risk behavior. Many studies have been done showing that adolescents who get high parental monitoring, causes less behavior risk rather than youth with low parental monitoring [13],[21]-[24].

Based on the theory of adolescent developmental psychology, early adolescence is the age when parents are still influential despite decreased by nearly $50 \%$ with the remainder being replaced by peers [25]. This study focuses on the early age of adolescence (13-15 years). This is supported by Piaget's theory of cognitive developments. Early adolescents are able to think abstractly, logically, and rationally. They are also able to use the hypothetical deductive [25].

\section{RESEARCH METHOD}

Quantitative research method with cross-sectional approach were used. This approach has been chosen to measure parental monitoring construct, which includes parental knowledge, monitoring behavior, psychological control, parent-adolescent relationship, parent-adolescent communication, premarital sexual behavior, subjective norms, sexual behavior intention, and adolescents' premarital sexual behavior that are measured in the same time.

Population in this research was all Junior High School students (age 13 to 15 years old) in Pontianak (7.593 adolescents). Proportionated random sampling was conducted among 402 adolescents of Junior High School at six subdistricts in Pontianak. Structural Equation Model (SEM) analysis was conducted using SMART-PLS version 2.0. It includes two phases: factor analysis and path analysis which is multiplied by 510 indicators/variables.

Samples had been choosen by Simple Random Sampling method. The following are steps in data collection. Firstly, all junior high school students lived in Pontianak were recorded, which are distributed in 6 subdistricts, i.e. North Pontianak, West Pontianak, South Pontianak, East Pontianak, Southeast Pontianak and Pontianak City (total 54 junior high schools). Secondly, samples were sorted and chosen randomly. There was only the appropriate sample with criteria used as the respondent of this research. The sample criteria were living with both parents (father and mother), parent's marital status married, and willing to participate in this research. Informed consent was given to adolescent and their parents. If one of them (parents or adolescents) do not agree to be involved, the respondents will not be included in this reseacrh.

Questionnaire was used as the instrument in this research. Before it was used, validity and reliability test of the instruments will be run first. This trial was conducted to 30 students at SMPN 7 in Singkawang. The result of validity test showed that there were few items are not valid. Therefore, these items were discarded and replaced with new items that also have to be tested again. The result showed that all items in the research instruments are valid and reliable $(r>0.3$ and alpha cronbach $>0.7$ ). 


\section{RESULTS AND ANALYSIS}

Results of research conducted on junior high school in Pontianak with a total sample of 402 respondents were distributed as shown on Table 1.

Tabel 1. Univariate Analysis

\begin{tabular}{|c|c|c|c|}
\hline No & Variable & $\mathrm{N}$ & $\%$ \\
\hline \multirow[t]{3}{*}{1.} & Gender & & \\
\hline & Male & 189 & 47.0 \\
\hline & Female & 213 & 53.0 \\
\hline \multirow[t]{3}{*}{2.} & Parental Knowledge & & \\
\hline & Low & 173 & 43.0 \\
\hline & High & 229 & 57.0 \\
\hline \multirow[t]{3}{*}{3.} & Parental Control & & \\
\hline & Low & 178 & 44.3 \\
\hline & High & 224 & 55.7 \\
\hline \multirow[t]{3}{*}{4.} & Communication between parental-adolescent & & \\
\hline & Low & 186 & 46.3 \\
\hline & High & 216 & 53.7 \\
\hline \multirow[t]{3}{*}{5.} & Relationship between parental-adolescent & & \\
\hline & Poor & 142 & 35.3 \\
\hline & Good & 260 & 64.7 \\
\hline \multirow[t]{3}{*}{6.} & Psychological control behaviour & & \\
\hline & Low & 121 & 30.1 \\
\hline & High & 281 & 69.9 \\
\hline \multirow[t]{3}{*}{7.} & Monitoring parental & & \\
\hline & Low & 185 & 46.0 \\
\hline & High & 217 & 54.0 \\
\hline \multirow[t]{3}{*}{8.} & Attitude toward premarital sexual & & \\
\hline & Permissive & 182 & 45.3 \\
\hline & Not permissive & 220 & 54.7 \\
\hline \multirow[t]{3}{*}{9.} & Subjective norms & & \\
\hline & Permissive & 183 & 45.5 \\
\hline & Not permissive & 219 & 54.5 \\
\hline \multirow[t]{3}{*}{10.} & Intention to behave & & \\
\hline & Premarital sexual & 77 & 19.2 \\
\hline & Not premarital sexual & 325 & 80.8 \\
\hline \multirow[t]{3}{*}{11.} & Premarital sexual behavior & & \\
\hline & Yes & 36 & 9.0 \\
\hline & No & 366 & 91.0 \\
\hline
\end{tabular}

Source: Primary data, 2015

Table 1 shows that the most of respondents were females (53.0\%), low perception about parental knowledge (43.0\%), low parental control (44.3\%), low parent-adolescent communication (46.3\%), low relationship between parental and adolescent (35.3\%), and low psychological control (30.1\%). Moreover, $46 \%$ respondents got low parental monitoring, permissive attitude toward premarital sexual (45.3\%), permissive subjective norm (45.5\%), had intention to premarital sexual (19.2\%), and premarital sexual bahavior (5.5\% kissing, 3.5\% necking, $2.7 \%$ petting, $2.2 \%$ oral sex, $1.5 \%$ anal sex, and $2.7 \%$ intercourse.

Multivariate analysis was used to analyze effects of independent variables and dependent variables at the same time. It was also used to determine dominant variables in relationship patterns within variables by using SEM (Structural Equation Model) analysis with SMART-PLS (Partial Least Square) version 2.0. A significant parameter estimated the relationship among variables. To test the hypothesis, output values of result for inner weight had been used. Estimated output of structural model testing can be seen on Table 2 and 3. Here is the results output estimation for testing the structural model: 


\begin{tabular}{|c|c|c|c|c|c|}
\hline & $\begin{array}{c}\text { Original } \\
\text { Sample } \\
\text { Estimate }(\mathrm{O}) \\
\end{array}$ & $\begin{array}{l}\text { Mean of Sub } \\
\text { samples (M) }\end{array}$ & $\begin{array}{l}\text { Standard } \\
\text { Deviation } \\
(\text { STDEV) } \\
\end{array}$ & $\begin{array}{l}\text { Standard Error } \\
\text { (STERR) }\end{array}$ & $\begin{array}{c}\text { T-Statistics } \\
\text { (|O/STERR } \mid \text { ) }\end{array}$ \\
\hline $\begin{array}{l}\text { Parent-adolescent relationship } \\
\text {-> Parental Monitoring }\end{array}$ & 0.334 & 0.333 & 0.023 & 0.023 & $14.218^{*}$ \\
\hline Parent-adolescent & & & & & \\
\hline $\begin{array}{l}\text { Communication -> Parental } \\
\text { Monitoring }\end{array}$ & 0.169 & 0.170 & 0.0151 & 0.0151 & $11.219 *$ \\
\hline Control -> Parental Monitoring & 0.263 & 0.261 & 0.021 & 0.021 & $12.805^{*}$ \\
\hline $\begin{array}{l}\text { Parental Knowledge -> } \\
\text { Parental Monitoring }\end{array}$ & 0.389 & 0.387 & 0.026 & 0.026 & $15.201^{*}$ \\
\hline $\begin{array}{l}\text { Parental psychological control } \\
\text {-> Parental Monitoring }\end{array}$ & 0.209 & 0.209 & 0.022 & 0.022 & $9.613^{*}$ \\
\hline $\begin{array}{l}\text { Parental monitoring -> } \\
\text { Subjective Norms }\end{array}$ & 0.391 & 0.397 & 0.048 & 0.048 & $8.204^{*}$ \\
\hline $\begin{array}{l}\text { Parental monitoring -> sexual } \\
\text { behavior }\end{array}$ & -0.003 & -0.002 & 0.073 & 0.073 & 0.039 \\
\hline Parental monitoring -> attitude & 0.386 & 0.390 & 0.045 & 0.045 & $8.661^{*}$ \\
\hline intention -> sexual behavior & 0.282 & 0.299 & 0.076 & 0.076 & $3.728 *$ \\
\hline Subjective Norms -> Intention & 0.107 & 0.106 & 0.057 & 0.057 & 1.867 \\
\hline $\begin{array}{l}\text { Subjective Norms ->sexual } \\
\text { behavior }\end{array}$ & 0.074 & 0.077 & 0.058 & 0.058 & 1.270 \\
\hline Attitude -> intention & 0.310 & 0.311 & 0,043 & 0.043 & $7.180^{*}$ \\
\hline Attitude -> sexual behavior & 0.164 & 0.164 & 0.080 & 0.080 & $2.044 *$ \\
\hline
\end{tabular}

Source: data processing by using SMART-PLS, 2015

Based on Table 2, parental knowledge, parent-adolescent relationship, parent-adolescent communication, parental control, and parental psychological control were significantly dan positively affected to parental monitoring (T-statictic more than 1.96). Parental knowledge (0.389) and parentadolescent relationship (0.334) had the biggest affected to parental monitoring. Parental monitoring had positively and significantly affected to adolescents' subjective norms and attitude about premarital sexual. Adolescent sexual behavior were positively and significantly affected by attitude about premarital sexual and intention to sexual behavior (t-statictic more than 1.96). Then, parental monitoring didn't have significantly direct relationship with adolescents' sexual behavior.

Table 3. Indirect structural model result

\begin{tabular}{lc}
\hline \multicolumn{1}{c}{ Path } & Coefficient \\
\hline Parental Monitoring $\rightarrow$ Attitude toward premarital sexual $\rightarrow$ Sexual & 0.063 \\
Behavior & \\
Parental Monitoring $\rightarrow$ Attitude toward premarital sexual $\rightarrow$ & 0.03 \\
intention to behave $\rightarrow$ Sexual Behavior
\end{tabular}

Source: data processing by manual calculation, 2015

Based on Table 3, analysis results indicated that parental monitoring had a significant indirect relationship with adolescent premarital sexual behavior through attitudes about premarital sexual (path coefficient $=0.063$ ), and attitudes about premarital sexual and intention to sexual behaviour (path coefficient $=0.03$ ). Parental monitoring variable can act as preventive factor of premarital sex behavior on adolescents.

\subsection{Parental monitoring}

Parental monitoring is conceptualized as "a set of correlated parenting behaviors involving attention to and tracking of the child's whereabouts, activities, and their friends" has the biggest correlation in parental monitoring (coeficient 0.389). Parental knowledge was protective against adolescent involvement in risk and problem behavior. This finding suggested that the actions of both adolescents and parents play prominent roles in yielding and eliciting monitoring knowledge and decreasing the likelihood of problem outcomes. Moreover, this knowledge was getting by child disclosure. Parental knowledge about their girl adolescent is higher than their boy adolescent (Odds Ratio $=2.906$; 95\% Confidence Interval $=1.931-4.374$ ). Contrast with previous researchs, there was a significantly relationship between sex and parental monitoring. Female adolescent get monitored more than male adolescent [26]-[32]. Problem and anti social behaviors are more on male adolescent than female [33]. Female adolescent tend to be closer to parents than male (Jacobson and Crockett, 2000). Normatively, Female is easier to have communication than male [34]. 
A further aspect in parental monitoring is the parental-adolescent relationship. The proportion of adolescent girls tend to have better relationship with their parents than boys $(\mathrm{OR}=2.138$ and $95 \% \mathrm{CI}=1.410$ to 3.242). Wright et al. (2006) stated that the relationship between parents with adolescents in many aspects of parental monitoring can predict adolescent sexual behavior [35]. It can be explained through the mechanism underlying this relationship. A less parental-adolescents relationship can increase adolescents' vulnerability to negative peer influence, and anti social behavior. Conversely, a good parental-adolescent relationship can delay adolescent's risky sexual behavior, reduce the frequency of intercourse and number of sexual partner [36]. This research showed a strong correlation and significant variables parental-adolescent relationship in the aspect of parental monitoring. It means that a good parental-adolescent relationship can make parental action in controlling the adolescent behavior influence on the reduction of risky behavior in adolescents [35].

In addition to parental relationships with parents, other aspects of parental monitoring is parentaladolescent communication. About $44,8 \%$ parents is still taboo when they will talk about sexual education with their adolescent. Some parents are uncomfortable or afraid to talk with their child about sexual activity. Some of them believe that talking about sex education as permission or encourages sexual activity in their children. These are myths. Reseach showed that talking with adolescent about sexual does not encourage them to be sexually active [37]. Adolescent girls have better communication with their parents than boys (OR $=2.732$ and $95 \% \mathrm{CI}=1.823$ to 4.095 ).

Th next aspect of parental monitoring is parental control. This study shows $33.1 \%$ of parents liberate curfew, providing the freedom to meet with the opposite sex as long as at home (25.4\%), freeing promiscuity (12.5\%), and not controlling adolescence (31.6\%). Female adolescent get higher the parental control than male $(\mathrm{OR}=1.866$ and $95 \% \mathrm{CI}=1.253$ to 2.779$)$. Contrast with Wamoyi et al. (2011) research, females (especially those still in school) receive parental controls more than males adolescent. It is influenced by the view that female adolescent will receive more severe consequences of problematic behavior (including risky sexual behavior) than male [36]. In addition, the focus of attention when the parents are not only at school, but also outside of school time. Inadequate parental monitoring can be a risk factor for adolescent development associated with behavioral problems, including risky sexual behavior [38]. Previous studies have shown that negative parenting behaviors can be predicted on adolescent problem behavior. This is related to the lack of parental involvement in adolescents, low control, perceived violence adolescents, and inconsistent discipline [39],[40]. Parental control is also associated with a delay intercourse or a reduction in the frequency of intercourse [41].

The last aspect in parental monitoring is psychological control. This study shows parents never expressed his expectation (18.9\%), and respondents are not ashamed if it can not be the intended parents (14.0\%). Female adolescent tend to get higher psychological control than males (OR $=1.617$ and $95 \% \mathrm{CI}=$ 1.053 to 2.484). In addition, low parental monitoring are also predicted early sexual activity for males and females adolescent, and for females to predict the number of sexual partners [35]. Parental monitoring of adolescent reduce the frequency of intercourse by limiting the chance of sexual activity.

This study is contrast with Keisner et al. (2009), there was a significant relationship with the parental monitoring of adolescent problem behaviors, including risky sexual behavior, indirectly [42]. Likewise, some research shows parental monitoring is not always directly related to the significant adolescent behavior in the multivariate analysis [43].

In summary, parental monitoring knowledge and parental monitoring behavior are distinct constructs in the greater domain of parental monitoring. Knowledge is defined as information parents obtain regarding their adolescents' whereabouts, activities, and associates. Investigators thus far have treated adolescents and parents as the basis for monitoring knowledge. Based on the discussion above, it can be concluded that parental monitoring can be a protective factor against adolescent premarital sexual behavior. Adequate parental monitoring can prevent adolescent conduct premarital sexual behavior. Therefore, it takes knowledge and parental understanding and skill in monitoring (including communication skills to improve the knowledge and relationships with adolescents).

\subsection{Attitude toward premarital sexual behavior}

The most of adolescents have permissive attitude toward premarital sexual (45.3\%). Bivariate analysis showed significantly dan positively correlation between attitudes about premarital sexual intercourse $(\mathrm{p}$ value $=0.0001$ and correlation coefficient $=0.279)$ and sexual behavior intention. Based on multivariate analysis using the PLS-SEM showed that there was significantly correlation between sexual attitude and intention of sexual behavior (values $t>1.96$ and path coefficient $=0.310$ ), and sexual behavior (values $t>$ 1.96 and path coefficient $=0.164)$. Male adolescent attitudes tend to be more permissive than female $(\mathrm{OR}=$ 2.031 and $95 \% \mathrm{CI}=1.363$ to 3.028 ). 
Adolescent's permissive sexual attitudes towards premarital sexual behavior can lead to the risky sexual behaviour. It can impact to unwanted pregnancy and sexually transmitted diseases (STDs). Attitudes are predictors of behaviour. Permissive attitudes toward premarital sexual behavior will be followed by behavior. Consistently with this research, adolescents who have permissive attitudes about premarital sexual tend to do premarital sexual behavior more than not permissive attitudes $(\mathrm{OR}=3.438$ and $95 \% \mathrm{CI}=1.316$ to 8.978).

Parental attitudes about sexual can predict adolescent sexual attitudes and behavior [44]. This is because the adolescence attitudes can be influenced by the values of the family and culture derived from personal experience [36]. Besides parents, Adolescent's attitudes and behaviour can be influenced by Peer's attitudes and behavior.

Research conducted by Ahrold and Meston (2010) showed that the difference in sexual behavior between men and women. Men have more liberal attitudes toward sex than women [45]. Sexual attitudes are measured through adolescent perceptions of the positive and negative effects of abstinence or sex experience [46]. Negative attitudes are formed, making teens prepare him into adulthood through seeking sexual experiences. Sexual attitudes and cultural values which formed filtered through the experiences of each day in a social context [36]. More permissive attitudes about sex can predict the level of adolescent sexual initiation intercourse.

\subsection{Subjective norms}

The most of adolescent's subjective norms were permissive toward premarital sexual (45.5\%). Based on multivariate analysis using the PLS-SEM showed that no significant relationship between subjective norms and intention to sexual behavior (values $\mathrm{t}<1.96$ ). Likewise, subjective norm relationships with adolescent sexual behavior.

According on respondents' answers regarding parents' subjective norms showed $22.9 \%$ of parents teens permit them alone with a girl/boy friend, permissive toward premarital sex (22.3\%), giving freedom in courtship as long as it does not get pregnant (41.3\%). In addition, peers' and environments' subjective norms as follows: premarital sex with a boyfriend (37.8\%), together with a boyfriend (41.5\%), permissive in courtship (41.1\%), having sex as proof of love (12.6\%), unwanted pregnancy is ordinary and reasonable (14.9\%), kissing (14.6\%), and teens who become pregnant outside of marriage is not a family disgrace (34.3 $\%)$. Male Adolescents tend to have more permissive subjective norms than female adolescents (OR $=1.911$ and $95 \% \mathrm{CI}=1.283$ to 2.844 ).

Adolescents' subjective norms can be influenced by the environmental. In some particular culture, premarital sexual is supported. The termination of pregnancy is allowed by someone who get unwanted pregnancy. Meanwhile, other cultures resist, virginity is regarded as something of high value [47]. Contrast with this research, adolescents tend to have a permissive subjective norms if they live in the permissive environmental toward premarital sexual behavior. Interaction families (parents) and peers may affect adolescent subjective norms, which can affect whether and when adolescents to initiate sexual (intercourse) [36].

Moreover, the environment can be a model and information source on sexual behavior. Permissive environment toward premarital sexual behavior was associated with the increasing frequency of sexual intercourse on male adolescent and higher unwanted pregnancy on female adolescent. Adolescents' perception about parental rejection toward sexual related to delay sexual intercourse. It will increase if the parents-adolescent relationship are close and attachment. Parents-adolescents relationship continue to be important into adolescent years. Secure attachment to parents in adolescence facilitates the transmission of positive values [48].

\subsection{Intention to behave}

Multivariate analysis showed a significantly and positively correlation between intention to premarital sexual behavior and adolescents sexual behavior (t value greater than 1.96 and path coefficient 0.282). Intention is the most predictor in adolescent initiation premarital sexual [49],[50]. Intention is indicate how to perform the behaviour. The intention is assumed as a motivating factor influencing behavior. Interventions change medium-high intentions will change the behavior of successful small to medium. Great effects and behavioral intention correlation of 0.57 . This shows the intention of the intervention on a larger change in behavior [51].

A persons's behaviour can be predicted by their intention [52]. In contrast with this research, adolescent who have intention to premarital sexual, are more likely to have premarital sexual behaviour. Older adolescents were reported more less to have positive intention than younger (less than 16 years old). 
Sexual intention is influenced by sexual attitudes and parents’ attitude [53]. Sexual behaviour are influenced by family and peers [13].

\section{CONCLUSION}

Based on the result research, female were reported higher levels of parental monitoring than male. Finally, that lower levels of perceived parental monitoring were associated with adolescent premarital sexual behavior. Parental monitoring can act as protective factor in early adolescent premarital sexual behavior. Therefore, risk reduction interventions with adolescents should include their parents to learn about monitoring skill and develop skill that will allow them to buffer negative influences. It is needed to find the effectively parental monitoring intervention to prevent adolescents' premarital sexual behavior. Parental monitoring is the primary prevention in adolescent premarital sexual behavior.

\section{ACKNOWLEDGEMENTS}

The author wishes to express gratefulness and thanks to the all of participation in this research. The authors are also grateful to authors/editors/publisher of all those articles, journals, and books from where the literature for this article has been reviewed and discussed.

\section{REFERENCES}

[1] UNFPA, "Population and Development National Progress in Implementating the ICPD Programme of Action", UNFPA, 2004

[2] Clifton, D., Hervish, A., “The World’s Youth: 2013 Data Sheet”, Population Reference Bereau, 2013.

[3] Centers for Disease Control and Prevention (CDC), "Youth risk behavior surveillance-United States", Surveillance summaries, 2006.

[4] American Academy of Pediatrics, “Contraception and Adolescent”, Pediatrics, vol/issue: 104(5), pp. 1161-1166, 1999.

[5] Guiella, G., Madise, N. J., "HIV/AIDS and Sexual-Risk Behaviors among Adolescents: Factors influencing the use of condoms in Burkina Faso”, Afr J Reprod Health, vol/issue: 11(3), pp. 182-196, 2007.

[6] Kinsman, S. B., Romer, D., Furstenberg, F. F., Schwarz, D. F., "Early sexual initiation: the role of peer norms", Pediatrics, vol/issue: 102(5), pp. 1185-1192, 1998.

[7] Kraft, P., "Age at first experience of intercourse among Norwegian adolescents: a lifestyle perspective", Soc Sci Med, vol/issue: 33(2), pp. 207-213, 1991.

[8] Miller, B. C., Norton, M. C., Curtis, T., Hill, E. J., Schvaneveldt, P., Young, M. H., "The Timing of sexual intercourse among adolescents: family, peer, and other antecedents”, Youth and Society, vol. 29, pp. 54-83, 1997.

[9] French, D. C., Dishion, T. J., "Predictor of Early Initiation of Sexual among High-Risk Adolescents", Journal of Early Adolescence, vol/issue: 23(3), pp. 295-315, 2003.

[10] Central Bereau of Statistic, International Macro, “Adolescence Reproductive Health Survey in 2007”, BPS dan Macro International, 2007.

[11] UNICEF Indonesia, “Summary: Response to HIV-AIDS”. Jakarta, 2012.

[12] The National Population and Family Planning, "Study of Adolescence Population Profile (10-24 years old): What's Up with Adolescence?”, Center of Population Reseach and Development, 2012.

[13] Suwarni, L., "The impact of Parental Monitoring and Peers to Premarital Sexual Behavior in Pontianak City", Indonesian Health Promotion Journal, Diponegoro University, 2009.

[14] French, D. C., Dishion, T. J., "Predictor of Early Initiation of Sexual among High-Risk Adolescents”, Journal of Early Adolescence, vol/issue: 23(3), pp. 295-315, 2003.

[15] Johnson, P. B., Malow-Irrof, M. S., “Adolescents and Risk. Making Sense of Adolescent Psychology”, London: Praeger, 2008.

[16] L’Engle, L. K., Brown, D. J., Kenneavy, K., “The mass media are an important context for adolescents' sexual behavior”, Journal of Adolescent Health, vol. 38, pp. 186 - 192, 2006.

[17] Kirby, D., Lepore, G., "Sexual Risk and Protective factors. Factors Affecting Teen Sexual Behavior, Pregnancy, Childbearing and Sexually Transmitted Disease: Which Are Important? Which Can You Change?”, Washington. DC: ETR Associates and The National Campaign to Prevent Teen and Unplanned Pregnancy, 2007.

[18] Jessor, R., Turbin, M. S., Costa, F. M., Dong, Q., et al., “Adolescent Problem Behavior in China and United States: A Cross-National Study of Psychosocial Protective Factors”, Journal of Research on Adolescence, vol/issue: 13(3), pp. 329-360, 2003.

[19] Brown, S. L., "Relationship between risk-taking behavior and subsequent risk perceptions", British Journal of Psychology, vol. 96, pp. 155-164, 2005.

[20] Miller, B. C., Benson, B. J., Galbraith, K. A., "Family relationship and adolescent pregnancy risk: A research synthesis”, Developmental Review, vol/issue: 21(1), pp. 1-38, 2001.

[21] Borawski, E A., Ievers-Landis, C. E., Lovegreen, L. D., Trapl, E. S., "Parental monitoring, negotiated unsupervised time, and parental trust: The role of perceived parenting practices in adolescent health risk behaviors", Journal of Adolescent Health, vol. 33, pp. 60 - 70, 2003. 
[22] Huebner, A. J., Howell, L. W., "Examining the relationship between adolescent sexual risk-taking and perceptions of monitoring, communication, and parenting style”, Journal of Adolescent Health, vol. 33, pp. 71 - 78, 2003.

[23] Jaccard, J., Dittus, P., "Parent-teen communication: Toward the prevention of unitended pregnancies”, New York: Springer-Verlag, 1991.

[24] Li, X., Stanton, B., Feigelman, S., "Impact of perceived parental monitoring on adolescent risk behavior over four years”, Journal of Adolescent Health, vol. 27, pp. 49 - 56, 2000.

[25] Santrock, J, W., “A Topical Approach to Life-Span Development”, 6th ed. McGraw-Hill Companies, 2012.

[26] Jacobson, K. C., Crockett, L. J., "Parental monitoring and adolescent adjustment: An ecological perspective", Journal of Research on Adolescence, vol. 10, pp. 65-97, 2000.

[27] Keijsers L., Branje S., Frijns T., Finkenauer C., Meeus W., "Gender differences in keeping secrets from parents in adolescence”, Developmental Psychology, vol. 46, pp. 293-298, 2010. [PubMed: 20053026].

[28] Kerr M., Stattin H., "What parents know, how they know it, and several forms of adolescent adjustment: Further support for a reinterpretation of monitoring”, Developmental Psychology, vol. 36, pp. 366-380, 2000. [PubMed: 10830980].

[29] Neumann, A., Barker, E. D., Koot, H. M., Maughan, B., “The role of contextual risk, impulsivity, and parental knowledge in the development of adolescent antisocial behavior”, Journal of Abnormal Psychology, vol. 119, pp. 534-545, 2010.

[30] Stattin, H., Kerr, M., "Parental monitoring: A reinterpretation”, Child Development, vol/issue: 71(4), pp. 10721085, 2000.

[31] Vieno, A., Nation, M., Pastore, M., Santinello, M., "Parenting and antisocial behavior: A model of the relationship between adolescent self-disclosure, parental closeness, parental control, and adolescent antisocial behavior", Developmental Psychology, vol. 45, pp. 1509-1519, 2009.

[32] Willoughby, T., Hamza, C. A., "A longitudinal examination of the bidirectional associations among perceived parenting behaviors, adolescent disclosure and problem behavior across the high school years”, Journal of Youth and Adolescence, vol. 4, pp. 463-478, 2011.

[33] Pettit G. S., Keiley M. K., Laird R. D., Bates J. E., Dodge K. A., "Predicting the developmental course of motherreported monitoring across childhood and adolescence from early proactive parenting, child temperament, and parents’ worries”, Journal of Family Psychology, vol. 21, pp. 206-217, 2007.

[34] Hinshaw, S. P., Lee, S. S., "Conduct and oppositional defiant disorders”, In E. J. Mash \& R. A. Barkley (Eds.), Child psychopathology (2nd ed., pp. 144-199). New York: Guilford Press, 2003.

[35] Wight, D., Williamson, L., Henderson, M., "Parental Influences on Young Peoples's Sexual Behavior: A Longitudinal Analysis”, Journal of Adolescence, vol. 29, pp. 473-494, 2006.

[36] Crockett, L. J., Raffaelli, M., Moilanen, K. L., “Adolescent Sexuality: Behavior and Meaning”, Faculty Publication, Departement of Psychology, Paper 245, 2003.

[37] Rai, A., Stanton, B., Wu, Y. Li, X., et al., "Relatives Influences of Perceived Parental Monitoring and Perceived Peer Involvement on Adolescent Risk Behaviors: An Analysis of Six Cross-Sectional Data Sets”, Journal of Adolescent Health, vol. 33, pp. 108-118, 2003.

[38] Racz, S. J., McMahon, R. J., "The relationship between parental knowledge and monitoring and child and adolescent conduct problems: a 10-year update”, Clinical Child and Family Psychology Review, vol. 14, pp. 377398, 2011.

[39] Hoeve, M., Dubas, J. S., Eichelsheim, V. I., van der Laan, P. H., Smeenk, W., Gerris, J. R. M., “The relationship between parenting and delinquency: A meta-analysis”, Journal of Abnormal Child Psychology, vol. 37, pp. 749775, 2009.

[40] Stormshak, E. A., Bierman, K. L., McMahon, R. J., Lengua, L. J., the Conduct Problems Prevention Research Group, "Parenting practices and child disruptive behavior problems in early elementary school”, Journal of Clinical Child Psychology, vol. 29, pp. 17-29, 2000.

[41] Jacobson, K. C., Crockett, L. J., "Parental monitoring and adolescent adjustment: An ecological perspective", Journal of Research on Adolescence, vol. 10, pp. 65-97, 2000.

[42] Kiesner, J., Dishion, T. J., Poulin, F., Pastore, M., "Temporal dynamics linking aspects of parent monitoring with early adolescent antisocial behavior”, Social Development, vol. 18, pp. 765-784, 2009.

[43] Small, S. A., Luster, T., “Adolescent sexual activity: An ecological, risk-factor approach”, Journal of Marriage and the Family, vol. 56, pp. 181-192, 1994.

[44] Weinstein, M., Thornton, A., "Mother-child relations and adolescent sexual attitudes and behaviors", Demography, vol/issue: 26(4), pp. 563-577, 1989.

[45] Ahrold, T. K., Meston, C., "Ethnic differences in sexual attitudes of U.S. college students: gender, acculturation, and religiosity factors”, Archives of Sexual Behavior, vol/issue: 39(1), pp. 190-202, 2010.

[46] Bonnie, L., Halpern-Felsher, Yan Reznik, "Sexual attitudes and behaviors: A developmental perspective", The prevention research, vol/issue: 16(4), pp. 1-6, 2009.

[47] Dittus. P. J., Jaccard, J., "The relationship of adolescent perceptions of maternal disapproval of sex and of the mother-adolescent relationship to sexual outcomes”, Manuscript, Department of Psychology, State University of New York at Albany, NY, 2000.

[48] Buhi, E. R., Goodson, P., "Predictors of adolescent sexual behavior and intention: A Theory-Guided Systematic Review”, Journal of Adolescent Health, vol. 40, pp. 4-21, 2007. 
[49] Mathews, C., Aaro, L. E., Flisher, A. J., Mukoma, W., Wubs, A. G., Schaalma, H., "Predictors of initiation Sexual behavior on Adolescent”, Health Education Research, vol. 24, pp. 1-10, 2009.

[50] Webb, T. L., Sheeran, P., "Does Changing Behavioral Intentions Engender Behavior Change? A meta-Analysis of the experimental evidence”, Psychological Bulletin, vol/issue: 132(2), pp. 249-268, 2006.

[51] Fisher, T. D., "An Extension of the finding of moore, Peterson, and Furstenberg (1986) regarding family sexual communication and adolescent sexual behaviour”, Journal of Marriage and Family, vol/issue: 51(3), pp. 637-639, 1989.

[52] Frankel, Anne S., "Predictors of Adolescent Sexual Intentions and Behavior: Attitudes, Parenting, and Neighborhood Risk", FIU Electronic Theses and Dissertations, Paper 771, 2012.

[53] Barman-Adhikari, A., Cederbaum, J., Sathoff, C., Toro, R., "Direct and indirect effects of maternal and peer influences on sexual intention among Urban African American and Hispanic females”, Child Adolesc Social Work Journal, vol/issue: 31(6), pp. 559-575, 2014. 